Biocontrol proteomics: development of an in situ interaction model and a protein extraction method for a proteomic study of the inhibiting mechanisms of Pichia anomala against Botrytis cinerea Anthony Kwasiborski, Mohammed Bajji, Pierre Delaplace, Patrick du Jardin, et al.

\section{BioControl}

Journal of the International

Organization for Biological Control

ISSN 1386-6141

Volume 57

Number 6

BioControl (2012) 57:837-848

DOI 10.1007/s10526-012-9460-4

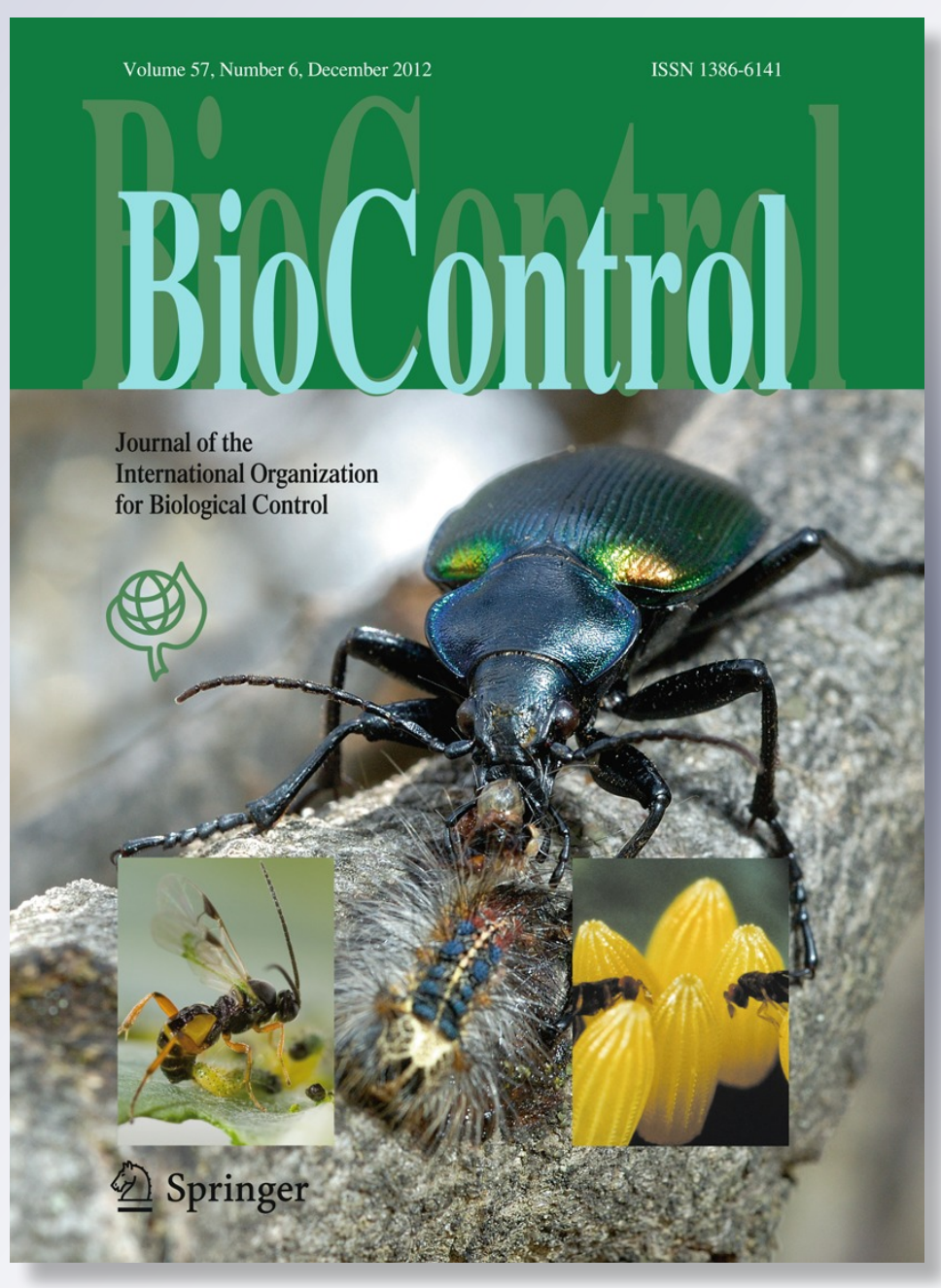

囪 Springer 
Your article is protected by copyright and all rights are held exclusively by International Organization for Biological Control (IOBC). This e-offprint is for personal use only and shall not be self-archived in electronic repositories. If you wish to self-archive your work, please use the accepted author's version for posting to your own website or your institution's repository. You may further deposit the accepted author's version on a funder's repository at a funder's request, provided it is not made publicly available until 12 months after publication. 


\title{
Biocontrol proteomics: development of an in situ interaction model and a protein extraction method for a proteomic study of the inhibiting mechanisms of Pichia anomala against Botrytis cinerea
}

\author{
Anthony Kwasiborski • Mohammed Bajji • \\ Pierre Delaplace $\cdot$ Patrick du Jardin • \\ Haïssam M. Jijakli
}

Received: 12 October 2011/Accepted: 27 April 2012/Published online: 16 May 2012

(C) International Organization for Biological Control (IOBC) 2012

\begin{abstract}
The biocontrol by Pichia anomala strain Kh6 (Hansen) Kurtzman (Saccharomycetales: Endomycetaceae) has been extensively studied using microbial, biochemical and molecular approaches. However, due to the complexity of the interaction process, the inhibition mechanism remains uncharacterized. An objective study based on proteomic techniques could allow to increase our knowledge. Studying modes of action requires conditions as close as possible to natural infection in order to take into account interactions between organisms implicating a more complex protein extraction procedure. In the present study, we developed an in situ model allowing the interaction between apple, antagonist and pathogen and maintaining the antagonist inhibitory effect while limiting the contaminations by the apple
\end{abstract}

Handling Editor: Choong-Min Ryu

A. Kwasiborski · H. M. Jijakli ( $\square)$

Plant Pathology Unit, Gembloux Agro-Bio Tech, University of Liège, Passage des Déportés, 2,

5030 Gembloux, Belgium

e-mail: mh.jijakli@ulg.ac.be

M. Bajji

Bioengineering Unit, Life Sciences Department, Wallon Agricultural Research Centre (CRA-W),

Chaussée de Charleroi, 5030 Gembloux, Belgium

P. Delaplace $\cdot$ P. du Jardin

Plant Biology Unit, Gembloux Agro-Bio Tech, University of Liège, Rue des Déportés, 2, 5030 Gembloux, Belgium components. Moreover, we set up an extraction protocol compatible with our in situ conditions and suitable for 2D analysis. Nine protocols, which differed in cell lysis or protein precipitation procedures, were compared on the basis of the protein yield, 1D gel quality and 2D gel quality.

Keywords Antagonism - In situ conditions · Pichia anomala strain Kh6 - Saccharomycetales: Endomycetaceae $\cdot$ Botrytis cinerea $\cdot$ Helotiales: Sclerotiniaceae $\cdot$ Proteomic study

\section{Introduction}

Botrytis cinerea Pers. (Helotiales: Sclerotiniaceae) is an ubiquist pathogen that causes grey mold disease during post-harvest storage of fruits (Sholberg and Haag 1996). Pichia anomala strain K (Hansen) Kurtzman (Saccharomycetales: Endomycetaceae) was identified as an antagonist of apple pathogens by our laboratory (Jijakli and Lepoivre 1993). The modes of action of $P$. anomala $\mathrm{K}$ on $B$. cinerea have already been studied using microbiological, biochemical and molecular approaches (Friel et al. 2007; Grevesse et al. 2003; Jijakli and Lepoivre 1998; Jijakli et al. 1999; Massart and Jijakli 2006). An in vitro study demonstrated that 11 transcripts of $P$. anomala presented an increased expression in the presence of $B$. cinerea cell walls (Massart and Jijakli 2006). The overexpressed genes showed homologies to yeast genes with various 
functions, including $\beta$-glucosidases, trans-membrane transport, citrate synthase and external amino acid sensing and transport. In vivo, two genes coding for $\beta$-glucanases, PAEXG1 and PAEXG2, seemed to be implied in the mode of action of $P$. anomala against B. cinerea (Friel et al. 2007). Indeed, the disruption of these genes separately or simultaneously implicated a severe decrease of the $P$. anomala protective effect. However, this study revealed the complexity of the mode(s) of action and suggested the involvement of other factors. Indeed, the protective level of the parent strain could be restored by increasing either the mutant yeast inoculum concentration or the physiological age of apples. To increase our knowledge about the mode(s) of action of $P$. anomala against $B$. cinerea, an in situ approach to study the host/pathogen/ antagonist triple interaction is required as well as a tool allowing to study the genome expression at a protein level without a priori (Friel et al. 2007).

Proteomics allows us to study the main part of cell protein contents and to observe variations in the proteome according to the different conditions of interest. However, for such studies, efficient protein extraction is crucial to ensure a successful separation by $2 \mathrm{D}$ and obtain well-resolved $2 \mathrm{D}$ gels, free of streaking or artefacts, and a reproducible protein pattern from gel to gel (Delaplace et al. 2006). Moreover the extraction procedure has to extract most of the cell protein content free of degradations and contaminants and has to be optimized for one organism, growth condition or cell compartment (Görg et al. 2004; Shaw and Riederer 2003).

The present study aims at developing an in situ model and an extraction protocol both compatible with the downstream proteomic study. The model should allow the interactions between the pathogen, its antagonist and apples, while maintaining the antagonist's inhibitory effect. It should also yield sufficient yeast quantity with a low level of apple contaminants in order to suit the proteomic study requirements. This model was based on a single large wound separated from the microorganisms by a membrane. The extraction protocol should allow to yield protein extracts quantitatively and qualitatively compatible with the proteomic study. Protocols differed mainly in the cell lysis and protein purification steps by adding either a sonication step or an organic precipitation to a basis protocol. A protocol already optimised for a proteomic study on potato tubers (Delaplace et al.
2006) was also included as a reference. The extraction protocols were compared on the basis of extracted protein yield, $1 \mathrm{D}$ gel quality and 2D gel quality.

\section{Materials and methods}

Organisms and culture conditions

The experiments were carried out in vivo on Malus pumila cv. Golden Delicious from a local supplier (van Dyck Freres SA, Namur, Belgium). For each experiment, $P$. anomala strain Kh6 was grown on Potato dextrose agar (PDA) medium for $24 \mathrm{~h}$ at $25^{\circ} \mathrm{C}$. After three successive subcultures under the same conditions, yeast colonies were scraped from plates and suspended in isotonic water $(0.85 \% \mathrm{NaCl})$. The concentration of the yeast suspension was adjusted to $10^{7} \mathrm{cfu} \mathrm{ml}^{-1}$ on the basis of optical density measurements on a PRIM934 spectrometer (Secomam, France) at $595 \mathrm{~nm}$. B. cinerea strain V was cultivated on PDA medium at $25^{\circ} \mathrm{C}$ for three weeks with a 16-h photoperiod. Before use, $0.05 \%$ Tween 20 solution were added onto the cultures. Spores were scraped off and suspensions were filtered through sterile nylon gauze. Spore concentration was estimated using a Bürker counting chamber (Marienfeld Laboratory Glassware, Lauda-Königshofen, Germany) and adjusted to $10^{6}$ spores $\mathrm{ml}^{-1}$ in $0.05 \%$ Tween 20 solution.

\section{Comparison model}

Apples were disinfected for $2 \mathrm{~min}$ in a $10 \%$ solution of $36^{\circ}$ sodium hypochlorite, washed twice in sterile distilled water and dried overnight. A large and round wound (diameter of $50 \mathrm{~mm}$ ) was cut out in the longitudinal section removing a $5 \mathrm{~mm}$ thick part of the apples and covered with a membrane (Supor 450, $47 \mathrm{~mm}, 0.45 \mu \mathrm{m}$, PALL, New York, USA). The apples were placed in plastic boxes containing paper moistured with $3 \mathrm{ml}$ of distilled water to maintain a high relative humidity. Four hundred microliters of the antagonist suspension were laid on the membrane. One hour later, the apples were inoculated with $400 \mu \mathrm{l}$ of the pathogen suspension (Kh6-B) or with $400 \mu \mathrm{l}$ of mock inoculums (Kh6). The apples were incubated at $25{ }^{\circ} \mathrm{C}$ for $7 \mathrm{~h}$ (exponential phase, Kh6-7 and Kh6B-7) or $24 \mathrm{~h}$ (stationary phase, Kh6-24 and Kh6B-24) after 
$P$. anomala Kh6 inoculation. The membranes were placed in centrifugation tubes containing $5 \mathrm{ml}$ of isotonic water and vortexed $\left(2,800 \mathrm{~min}^{-1}\right)$ for $20 \mathrm{~s}$ to recover the yeasts. After a centrifugation at $20,800 \times g$ for $10 \mathrm{~min}$ at $4{ }^{\circ} \mathrm{C}$, yeast pellets were washed with $1 \mathrm{ml}$ of ultra pure water prior to $-80{ }^{\circ} \mathrm{C}$ storage until use. To verify the inhibitory effect of $P$. anomala $\mathrm{Kh} 6$ on $B$. cinerea, pathogen mycelium development was assessed after seven days incubation in the same conditions on apples inoculated with $P$. anomala $\mathrm{Kh} 6$ in the presence of $B$. cinerea or with $B$. cinerea alone.

Growth time-course of $P$. anomala Kh6

Growth curves of $P$. anomala Kh6 were established using the in situ model in the presence or absence of B. cinerea. Three apples were used for each condition and incubation period. Yeast cells were recovered 0,3 , 6, 9, 12 and $15 \mathrm{~h}$ after apple treatment and the obtained suspensions were diluted to $10^{-3}(0,3,6$ and $9 \mathrm{~h})$ or $10^{-4}$ (12 and $15 \mathrm{~h}$ ). One hundred microliters of each dilution were plated on PDA medium and incubated at $25{ }^{\circ} \mathrm{C}$ for four days before counting colony forming units.

Protein extraction protocols

\section{Hot SDS/acetone protocol (Fig. 1a)}

The Hot SDS/acetone protocol (SDSprot) is based on the extraction protocol from Delaplace et al. (2006). Briefly, the yeast pellet was thawed on ice, then resuspended in $750 \mu \mathrm{l}$ of Lysis buffer 1 (LB1: $4 \% \mathrm{w} / \mathrm{v}$ SDS, $5 \% \mathrm{w} / \mathrm{v}$ sucrose, $0.3 \% \mathrm{w} / \mathrm{v}$ DTT, $10 \% \mathrm{w} / \mathrm{v}$ PVP-P, $20 \mathrm{mM}$ sodium phosphate, $\mathrm{pH}$ 8.0) preheated at $70{ }^{\circ} \mathrm{C}$ and added onto $750 \mu \mathrm{l}$ of glass beads (425-600 $\mu \mathrm{m}$, Sigma, St-Louis, Missouri, USA).

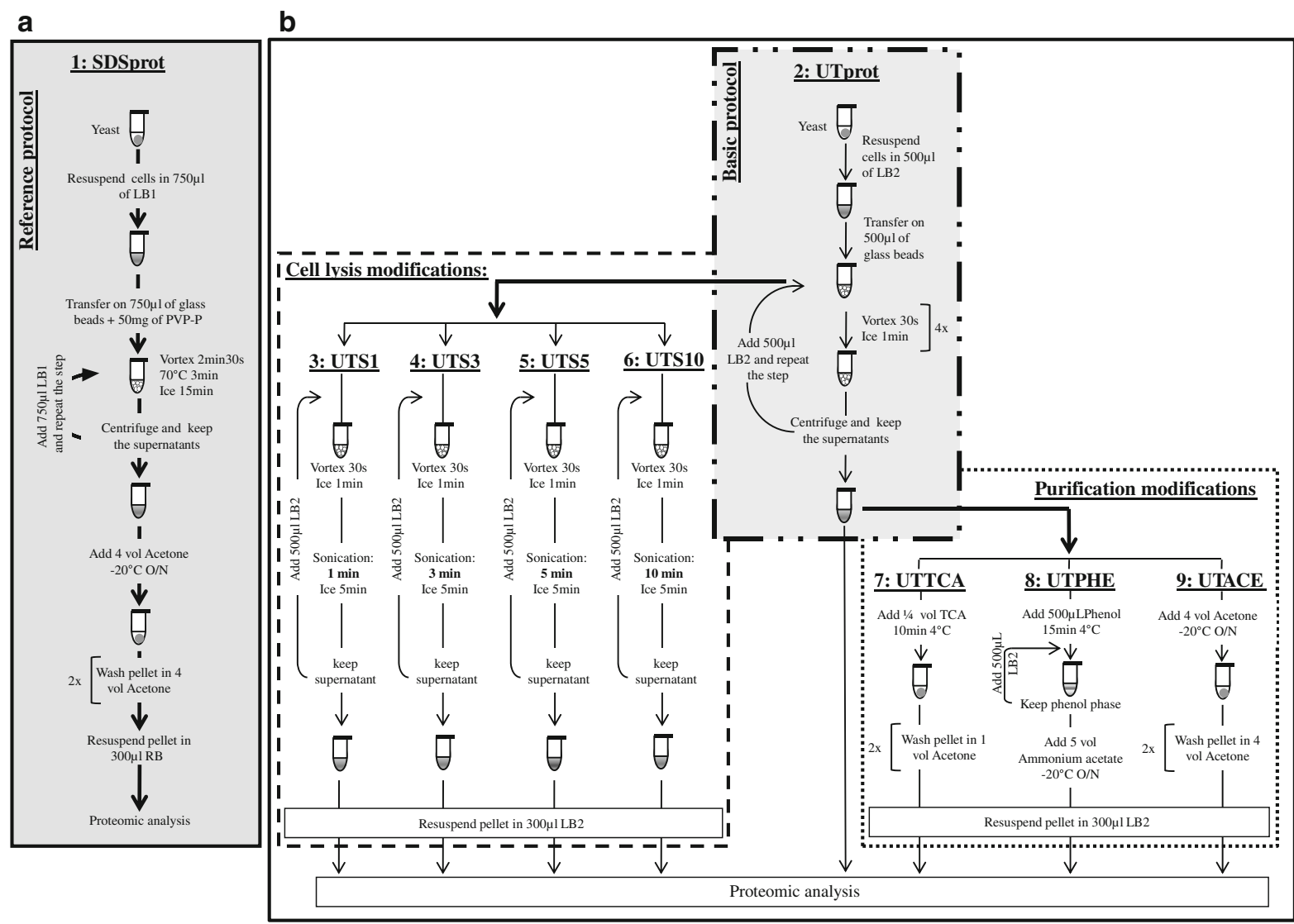

Fig. 1 Outline of (a) the Hot SDS/acetone extraction protocol (1: SDSprot), (b) the urea/thiourea extraction protocol (2: UTprot) and its modifications (3: UTS1, 4: UTS3, 5: UTS5, 6 :
UTS10, 7: UTTCA, 8: UTPHE and 9: UTACE). LB1 lysis buffer $1, R B$ rehydration buffer, $L B 2$ lysis buffer 2 
The mix was homogenized for $2.5 \mathrm{~min}$ on a Mini Beadbeater- 8 (Biospec Products, Bartlesville, Oklahoma, USA) then heated at $70{ }^{\circ} \mathrm{C}$ for $3 \mathrm{~min}$, placed on ice for $15 \mathrm{~min}$ and centrifuged at $16,100 \times g$ for $1 \mathrm{~min}$ at $4{ }^{\circ} \mathrm{C}$. The supernatant was transferred into a new Eppendorf tube. The extraction was repeated once by adding $750 \mu \mathrm{l}$ of preheated LB1 on the glass beads again. The resulting supernatants were pooled and then cleared by centrifugation $(16,100 \times g, 15 \mathrm{~min}$, $4{ }^{\circ} \mathrm{C}$ ) before overnight precipitation at $-20{ }^{\circ} \mathrm{C}$ using four volumes of $10 \mathrm{mM}$ DTT cold acetone. After a new centrifugation $\left(20,800 \times g, 20 \mathrm{~min}, 4{ }^{\circ} \mathrm{C}\right)$, the protein pellet was washed twice with cold acetone/ DTT solution, dried and solubilized in $300 \mu \mathrm{l}$ of rehydration buffer (RB1; 7 M Urea, $2 \mathrm{M}$ Thiourea, $4 \%$ CHAPS and $20 \mathrm{mM}$ DTT). The samples were stored at $-80{ }^{\circ} \mathrm{C}$ until use.

\section{Urea/Thiourea protocol (Fig. 1b)}

The urea/thiourea protocol (UTprot) was based on those previously used for yeast protein extraction (Fernández-Arenas et al. 2007; Gori et al. 2007; Hansen et al. 2006; Hu et al. 2003; Hwang et al. 2006; Kusch et al. 2007; Matis et al. 2005; Orsborn et al. 2006; Sinclair et al. 2006; Teixeira et al. 2005). Briefly, after thawing on ice, the yeast pellet was resuspended in $500 \mu \mathrm{l}$ of Lysis buffer 2 (LB2; $7 \mathrm{M}$ Urea, 2 M Thiourea, $4 \%$ CHAPS, $20 \mathrm{mM}$ DTT and a protease inhibitor cocktail (complete mini tablets, Roche applied Science, Penzberg, Germany)) and transferred onto $500 \mu \mathrm{l}$ of glass beads. Four 30-sec homogenization cycles using the Mini Beadbeater- 8 with 1-min stages on ice in-between were performed on the homogenate before centrifuging $(16,100 \times g$, $1 \mathrm{~min}, 4{ }^{\circ} \mathrm{C}$ ) and transferring the supernatant into a new eppendorf tube. An additional extraction step was performed by adding $500 \mu \mathrm{l}$ of fresh LB2 on the remaining glass beads. The resulting supernatants were pooled, cleared $\left(16,100 \times g, 15 \mathrm{~min}, 4{ }^{\circ} \mathrm{C}\right)$ and stored at $-80{ }^{\circ} \mathrm{C}$ until use.

\section{Optimization of the UTprot (Fig. 1b)}

Two approaches were chosen to optimise the quantity and quality of extracted proteins: modifying cell lysis or adding protein precipitation steps. Cell lysis was modified by adding a sonication step. After the yeast pellet was resuspended, transferred onto glass beads and homogenized, the mix was placed in a $45 \mathrm{kHz}$ ultrasonic bath (VWR international, West Chester, Pennsylvania, USA) for $1 \mathrm{~min}$ (UTS1), $3 \mathrm{~min}$ (UTS3), 5 min (UTS5) or $10 \mathrm{~min}$ (UTS10). An additional extraction step was performed in each case and the obtained supernatants were cleared $(16,100 \times g$, $15 \mathrm{~min}, 4{ }^{\circ} \mathrm{C}$ ) and stored at $-80{ }^{\circ} \mathrm{C}$.

Protein purification was modified by adding a precipitation step using trichloroacetic acid (TCA), phenol- or acetone-based methods. TCA precipitation (UTTCA) was performed by adding $1 / 4$ volume of $100 \%$ TCA solution to the supernatants for $10 \mathrm{~min}$ at $4{ }^{\circ} \mathrm{C}$. After two washes of the precipitate in cold acetone, proteins were solubilised in $300 \mu \mathrm{l}$ of LB2 and stored at $-80{ }^{\circ} \mathrm{C}$. The phenol-based method (UTPHE) was performed by adding $500 \mu \mathrm{l}$ of saturated phenol solution (trisCl $50 \mathrm{mM}, \mathrm{pH}$ 8) for $15 \mathrm{~min}$ at $4{ }^{\circ} \mathrm{C}$ to the supernatants. Five hundred microliters of LB2 were added before precipitating the proteins overnight at $-20{ }^{\circ} \mathrm{C}$ by adding five volumes of ammonium acetate. After a centrifugation $(6,000 \times g$, $3 \mathrm{~min}, 4{ }^{\circ} \mathrm{C}$ ), proteins were solubilised in $300 \mu \mathrm{l}$ of LB2 and stored at $-80{ }^{\circ} \mathrm{C}$. Acetone precipitation (UTACE) was performed in the same conditions as in the SDS protocol. Protein concentrations were determined using the Bradford method (Bradford 1976). Each extraction were carried out in two repetitions.

\section{$1 \mathrm{D}$ and $2 \mathrm{D}$ electrophoresis}

1D electrophoresis was performed by loading $2 \mu \mathrm{g}$ of proteins complemented with $25 \%$ of NuPAGE ${ }^{\circledR}$ LDS Sample Buffer (Invitrogen, San Diego, California, USA) in each well of the NuPAGE Novex 4-12\% Bis-tris Gel $1.0 \mathrm{~mm}$, ten wells (Invitrogen) according to the manufacturer's instructions on the XCell SureLock Mini-Cell (Invitrogen). The gels were stained using the SilverXpress staining kit (Invitrogen). Gels were carried out in duplicate.

2D electrophoresis was performed using either 7- or 24-cm gels. For the 7-cm gels, the isolectric focusing (IEF) was carried out using 7-cm long pH 4-7 IPG strips (GE Healthcare, Little Chalfont, UK). The strips were passively rehydrated $\mathrm{O} / \mathrm{N}$ in $7 \mathrm{~cm}$ strip holders (GE Healthcare) with $5 \mu \mathrm{g}$ of total proteins complemented with $0.5 \%$ of IPG buffer $\mathrm{pH}$ 4-7 (GE Healthcare) and diluted in RB or LB2, according to the extraction protocol, to reach a final volume of $125 \mu \mathrm{l}$. After rehydration, the focusing was performed 
on the Ettan IPGphor II (GE Healthcare) using the following conditions: $30 \mathrm{~V}$ for $2 \mathrm{~h}$, a gradient to $500 \mathrm{~V}$ within $1 \mathrm{~h}$, a gradient to $4,000 \mathrm{~V}$ within $1.5 \mathrm{~h}$, a gradient to 5,000 V within $30 \mathrm{~min}$ and 5,000 V until a total of $15,000 \mathrm{~V} \mathrm{~h}^{-1}$ was reached. Before the second dimension, the strips were first equilibrated for $15 \mathrm{~min}$ in $5 \mathrm{ml}$ equilibration buffer (6 M urea, $30 \%$ glycerol, $2 \%$ SDS, $50 \mathrm{mM}$ Tris $\mathrm{pH} 8.8$ ) containing $1 \% \mathrm{w} / \mathrm{v}$ DTT and second for $15 \mathrm{~min}$ in $5 \mathrm{ml}$ equilibration buffer containing $2.5 \% \mathrm{w} / \mathrm{v}$ iodoacetamide. The second dimension was obtained on the XCell SureLock Mini-Cell (Invitrogen) using a NuPAGE Novex $12 \%$ Bis-tris Gel $1.0 \mathrm{~mm}$, one well (Invitrogen). Migration was carried out $30 \mathrm{~min}$ at $30 \mathrm{~V}$ and $50 \mathrm{~min}$ at $200 \mathrm{~V}$. The gels were individually stained using the SilverXpress staining kit (Invitrogen).

For the 24-cm gels, the IEF was performed using 24-cm long $\mathrm{pH}$ 4-7 IPG strips, passively rehydrated $\mathrm{O} / \mathrm{N}$ on a rehydratation tray (GE Healthcare) with $100 \mu \mathrm{g}$ of total proteins complemented with $2 \%$ of IPG buffer $\mathrm{pH} 4-7$, and then RB was added to reach a final volume of $450 \mu \mathrm{l}$. Focusing was performed on an Ettan IPGphor II using the following programme: $50 \mathrm{~V}$ for $3 \mathrm{~h}, 300 \mathrm{~V}$ for $3 \mathrm{~h}$, a gradient to $1,000 \mathrm{~V}$ within $6 \mathrm{~h}$, a gradient to $8,000 \mathrm{~V}$ within $3 \mathrm{~h}$, and $8,000 \mathrm{~V}$ until a total of $100,000 \mathrm{~V} \mathrm{~h}^{-1}$ was reached. Equilibration was performed in a $10-\mathrm{ml}$ volume per strip, in the same conditions as for the 7-cm gels. The second dimension was performed using 2DGel DALT NF $12.5 \%$ (Gel company, San Francisco, USA) on the Ettan DALT six (GE healthcare) using the following migration conditions: $1 \mathrm{~h}$ at $0.5 \mathrm{~W}$ per gel then $14 \mathrm{~h}$ at $2.5 \mathrm{~W}$ per gel. The gels were individually stained using Lavapurple (Fluorotechnics, Gladesville, Australia) following the manufacturer's recommendations. Each 2D gels were carried out in one repetition.

\section{Maldi-ToF mass spectrometry}

The mass spectrometry identification were carried out by the proteomic platform based in the Centre de Recherche Publique G. Lippmann (Belvaux, Luxembourg). Spot of interest were excised and the proteins were subjected to in-gel tryptic digestion. After washing and desalting in $50 \mathrm{mM}$ ammonium bicarbonate $/ 50 \% \mathrm{v} / \mathrm{v}$ methanol, followed by $75 \% \mathrm{v} / \mathrm{v}$ ACN, spots were then digested with $10 \mathrm{ng} / \mu \mathrm{l}$ Trypsin Gold (MSgrade, Promega, Madison, WI, USA) in $20 \mathrm{mM}$ ammonium bicarbonate. The peptides were extracted using a $50 \%$ ACN containing $0.1 \%$ TFA and analysed using the Applied Biosystems 4800Proteomics Analyser (Applied Biosystems, Foster City, CA, USA). Calibration was carried out with the peptide mass calibration kit for 4,700 (Applied Biosystems). Proteins were identified from their peptide mass fingerprinting and searching the NCBI protein sequence database using the MASCOT software (Matrix Science, http://www.matrixscience.com, London, UK). The search parameters allowed for carboxyamidomethylation of cysteine as fixed modification and Oxidation of methionine, oxidation, dioxydation and kynurenin of tryptophan as variable modifications.

\section{Results}

In situ model

Figure 2 presents the growth time-course of $P$. anomala $\mathrm{Kh} 6$ in the presence or absence of $B$. cinerea on the developed apple model. $P$. anomala Kh6 grew in the same way in the absence and presence of $B$. cinerea and showed the usual phases, i.e. latent $(0-2 \mathrm{~h})$, exponential $(2-10 \mathrm{~h})$ and stationary (from $10 \mathrm{~h}$ onward). Compared to the in situ model based on two wounds of $6 \mathrm{~mm}$ diameter used by (Jijakli and Lepoivre 1993; Jijakli et al. 1993) to study the

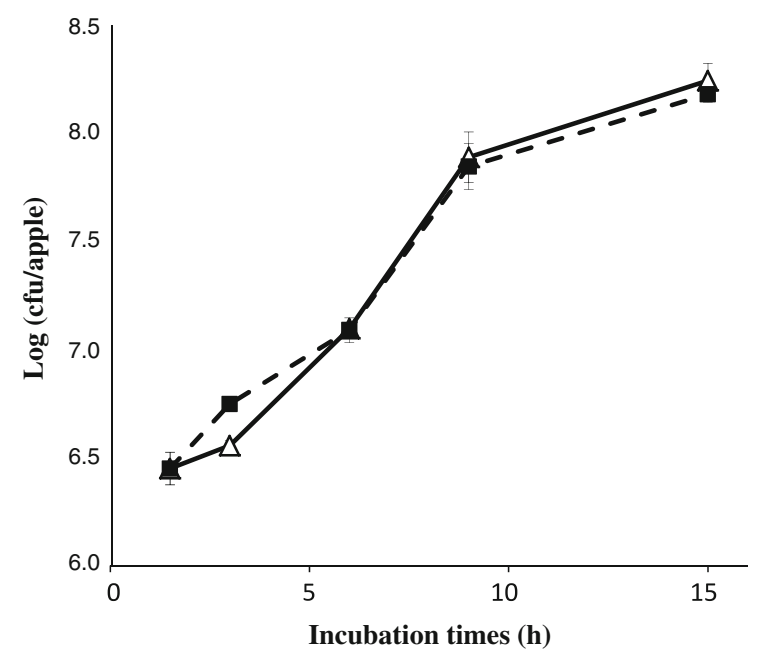

Fig. 2 Growth time-course of P. anomala Kh6 in the presence (triangle) or absence (filled square) of $B$. cinerea using the apple comparison model. Vertical bars indicate the SD of the log (cfu/ apple) determined as a mean of three measurements 
protective effect of $P$. anomala against $B$. cinerea, the developed model allowed to apply tenfold more yeast inoculum per wound and to recover 42- and 126-fold more yeast per wound in the exponential and stationary phase respectively (data not shown) while conserving the microorganisms inoculums/wound surface ratio.

\section{Extraction protocols comparison}

To identify an effective extraction protocol compatible with our in situ model and with the proteomic study, protocols were compared based on three parameters: protein yield, 1D gel quality and 2D gel quality.

\section{Protein yield}

Figure 3 presents the protein concentrations obtained with SDSprot, UTprot and UTprot modifications. SDSprot-extracted protein yields were from 2.7(Kh6-24) to 9.6-fold (Kh6B-7) more than when using UTprot. SDSprot- and UTprot-extracted protein yields were respectively twofold less and 1.4-fold more at the stationary phase (Kh6-24 and Kh6B-24) than at the exponential phase (Kh6-7 and Kh6B-7) and were respectively 2.0- and 1.6-fold more from samples with $P$. anomala $\mathrm{Kh} 6$ in the presence of $B$. cinerea $(\mathrm{Kh} 6 \mathrm{~B}-7$ and Kh6B-24) than from samples in the absence of the pathogen (Kh6-7 and Kh6-24). Adding a sonication step to our basic protocol increases protein yield (Fig. 3). The four protocols with a sonication step, UTS10, UTS5, UTS3 and UTS1, respectively increased protein yield by an average 7.7-, 9.5-, 2.9and 3.3-fold as compared to UTprot (Fig. 3). Longer sonication times did not increase the quantities of extracted proteins. On an average, UTS5-extracted protein yield was 1.2-fold more than UTS10- and for Kh6B-7 UTS1-extracted protein yield was 1.6-fold more than UTS3. Likewise, the three protocols with a precipitation step made it possible to increase extracted protein yield as compared to UTprot (Fig. 3). On an average, UTTCA-, UTPHE- and UTACE-extracted protein yields were respectively 2.6-, 3.2- and 3.7-fold more than UTprot yield. On an average, the UTPHE-extracted protein yield was

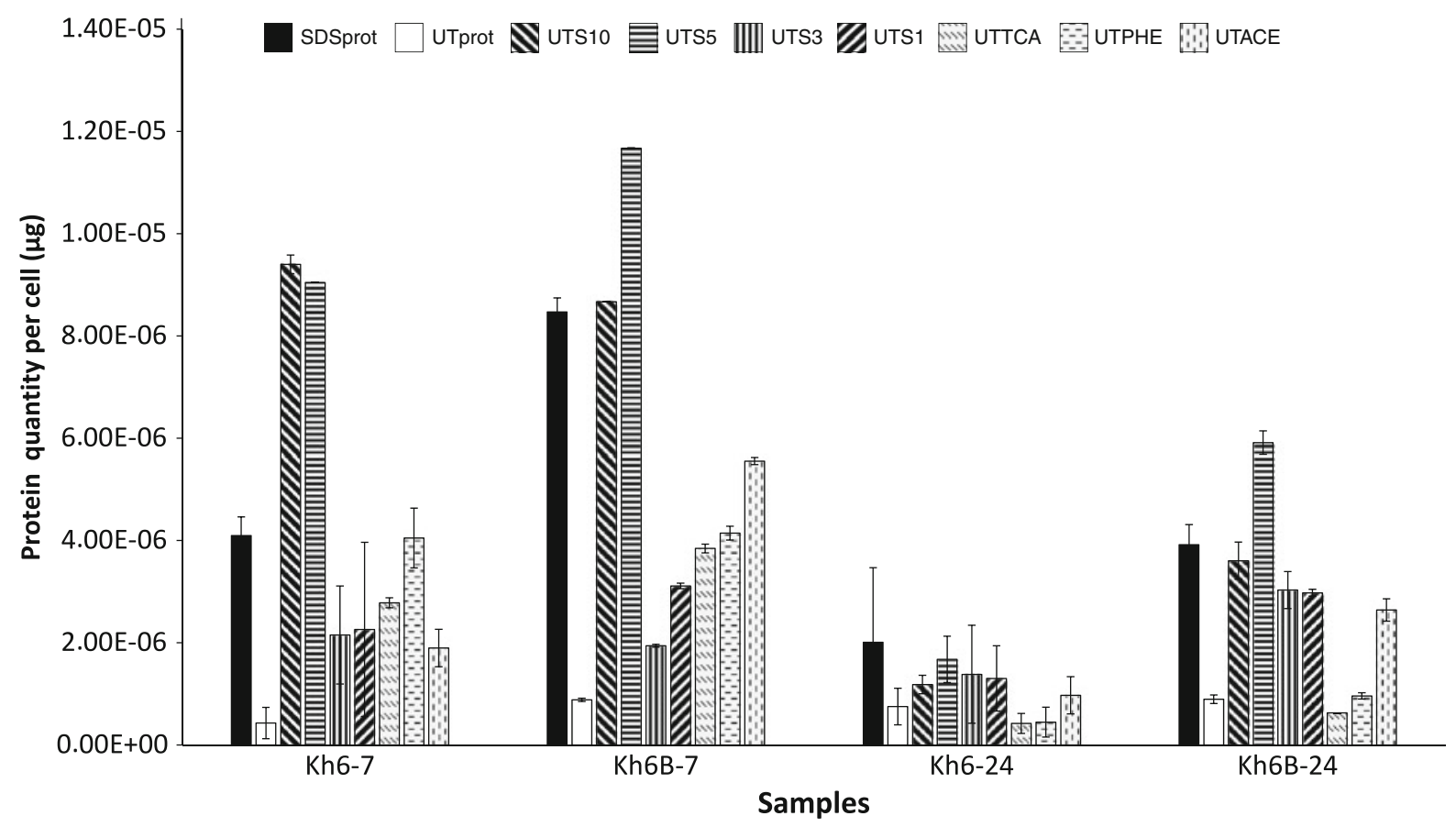

Fig. 3 Extracted protein yield per cell ( $\mu$ g prot/cell) using the different protocols. Vertical bars indicate the SD of the protein yield per cell determined as a mean of two replicates. UTprot urea/thiourea prot, SDSprot hot SDSprot, UTS10-5-3-1 sonication for 10, 5, 3, $1 \mathrm{~min}$, UTTCA TCA precipitation, UTPHE phenol precipitation, UTACE acetone precipitation 
1.2-fold more than the UTTCA- and, except for Kh67, UTACE yielded higher protein quantities than UTTCA or UTPHE.

\section{$1 D$ gel electrophoresis}

1D gel quality obtained using SDSprot, UTprot and UTprot modifications showed clear differences whatever the samples (Fig. 4). UTprot presented a protein population spanning a wide range of molecular weights (MW), from 2 to $200 \mathrm{kDa}$ whereas SDSprot extracted a majority of low MW proteins, from 2 to $35 \mathrm{kDa}$. The four sonication protocols (UTS10, 5, 3 and 1) showed few resolved bands. However, the short sonication times, UTS3 and UTS1, generated better sample quality (Kh6-7 for UTS3 or Kh6B-7 for UTS1) showing resolved, though less intense bands than long sonication time. Except for UTTCA, our precipitation protocols showed different gel patterns compared to UTprot. UTTCA presented distinct bands spanning a

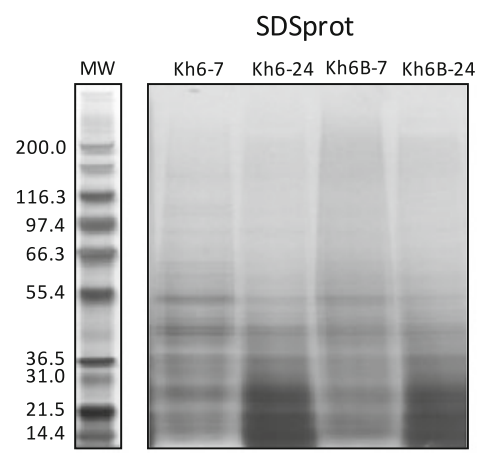

UTS10

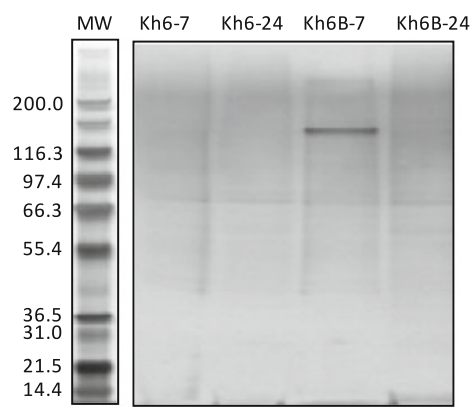

UTTCA

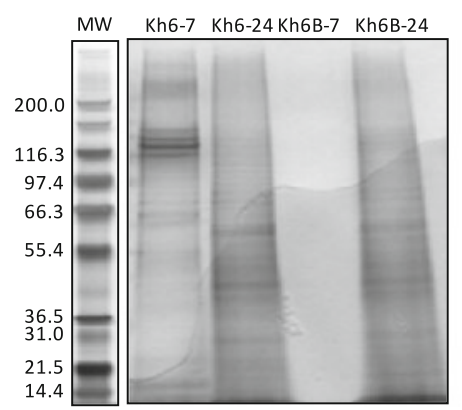

UTprot

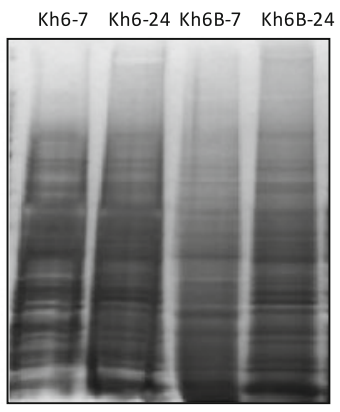

UTS5

Kh6-7 Kh6-24 Kh6B-7 Kh6B-24

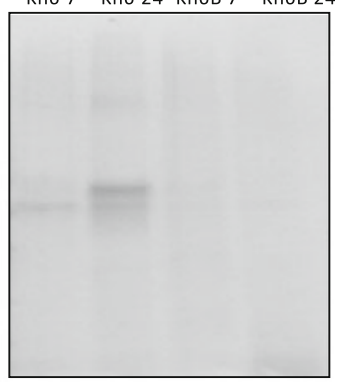

UTPHE

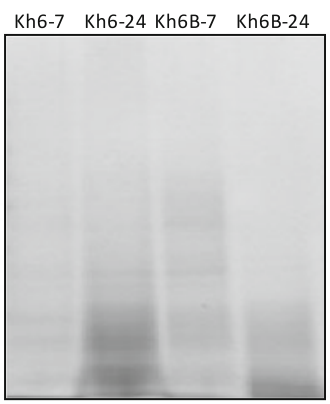

UTS3

Kh6-7 Kh6-24 Kh6B-7 Kh6B-24

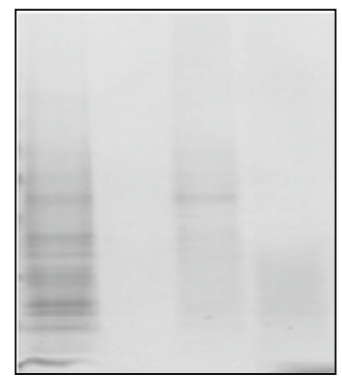

UTACE

Kh6-7 Kh6-24 Kh6B-7 Kh6B-24
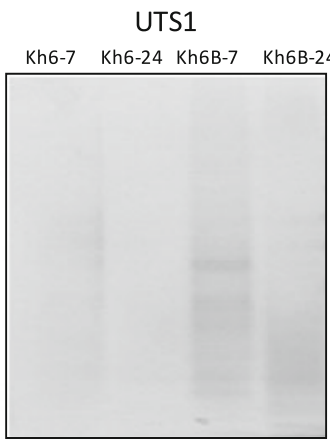

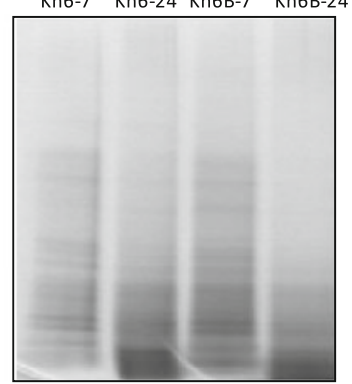

Fig. 4 1D gels of proteins extracted from Kh6-7, Kh6-24, Kh6B-7 and Kh6B-24 using the Hot SDSprot, the UTprot and its modifications (UTS10-5-3-1, UTTCA, UTPHE and UTACE).
NuPAGE Novex 4-12\% Bis-tris gels (Invitrogen) were used, loaded with $5 \mu \mathrm{g}$ of proteins and stained using the SilverXpress staining kit (Invitrogen) 
wide range of MWs, from 2 to $200 \mathrm{kDa}$ but with weak band intensity. UTPHE and UTACE generated wellresolved bands for all conditions (Kh6-7, Kh6B-7, Kh6-24 and Kh6B-24) but with low MWs (from 2 to $60 \mathrm{kDa}$ ) and weak band intensity.

\section{$7 \mathrm{~cm} 2 \mathrm{D}$ gel electrophoresis}

Each approach (basis protocols or sonication or precipitation) was evaluated in $2 \mathrm{D}$ but only the SDSprot, UTprot, UTS3 and UTACE gels are presented here (Fig. 5a). Except for these protocols, none of the modifications brought out spots. Whatever the sample conditions, SDSprot generated a low background and 123 well-resolved protein spots that spread from $\mathrm{pH} 4$ to 7 , with a wide range of molecular weights (Fig. 5a). However, low MW proteins were the predominant species in SDSprot 2D gels. A slight smear was also observed for high MWs and acidic proteins. UTprot generated 91 well-resolved protein spots spanning from $\mathrm{pH} 4$ to 7 and high MW proteins were the predominant extracted species whatever the samples (Fig. 5a). UTS3 and UTACE presented respectively 14 and 35 resolved spots, which is much lower than the SDSprot and UTprot resolved-spot numbers.

\section{$24 \mathrm{~cm} 2 \mathrm{D}$ gel electrophoresis}

Figure $5 \mathrm{~b}$ represents two representative gels obtained from Kh6B-7 to Kh6B-24 samples extracted using SDSprot. Whatever the sampling conditions, SDSprot generated a low background and well-resolved protein spots that spread from $\mathrm{pH} 4$ to 7 and on a wide molecular weight range. Unlike in the $7-\mathrm{cm} 2 \mathrm{D}$ pattern, we did not observe a predominance of the low molecular weight proteins. Moreover a higher number of protein spots were observed compared to the 7-cm gels.
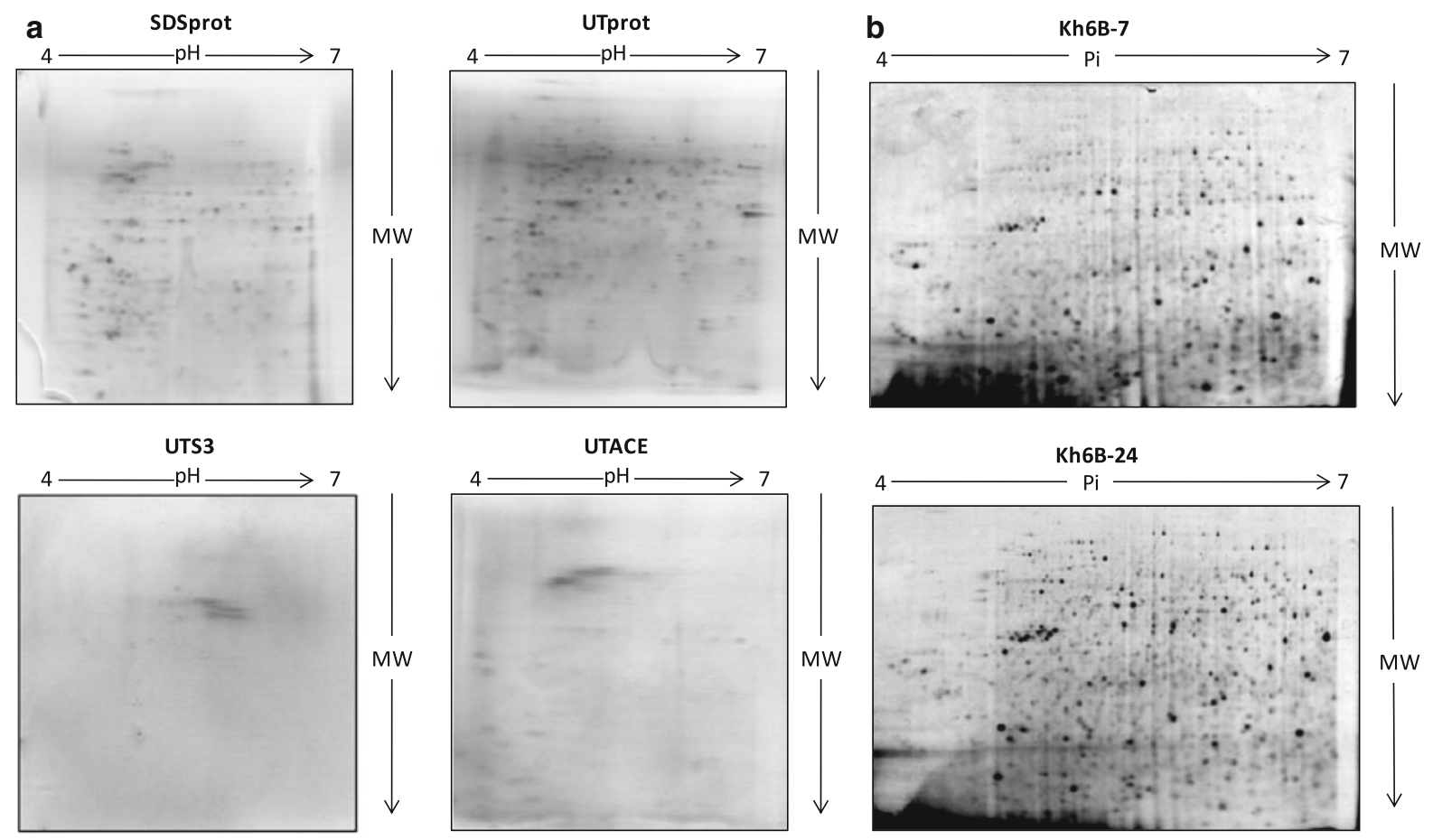

Fig. 5 7-cm 2D gels from Kh6-7 using Hot SDS/acetone (SDSprot), Urea/Thiourea (UTprot) and two modified (UTS5 and UTACE) protocols (a), and 24-cm 2D gels from Kh6B-7 and Kh6B-24 using the Hot SDS/acetone extraction protocol (b), 5 or $100 \mu \mathrm{g}$ of proteins were loaded on 7 -or $24-\mathrm{cm}$ IPG strips ( $\mathrm{pH} 4-7$ ) respectively, then run respectively on a NuPAGE Novex $12 \%$ Bis-tris Gel (Invitrogen) or 2DGel DALT NF $12.5 \%$ (Gel company) and finally stained using the SilverXpress staining kit (Invitrogen) or the Lavapurple (Fluorotechnics) respectively 


\section{Discussion}

The aim of this study was to develop an in situ model and a protein extraction protocol to perform the proteomic analysis of the antagonistic mechanisms exhibited by $P$. anomala $\mathrm{Kh} 6$ in the presence of the targeted pathogen $B$. cinerea, taking into account the apple/antagonist/pathogen tripartite interaction.

In situ model

The developed in situ model had to allow exchanges between organisms, to maintain the inhibitory effect of the antagonist, to obtain yeast quantity compatible with the downstream proteomic study and to limit the apple constituents' contaminations. Our model was based on a single large wound covered by a membrane separating the apple from the microorganisms and answered to the later prerogatives.

The membrane allowed the transfer of nutrients required for yeast and fungus growth and the conservation of the inhibitory effect of $P$. anomala against $B$. cinerea. Indeed, we observed the development of mycelium on the membrane inoculated with $B$. cinerea alone, which was severely reduced in the presence of $P$. anomala Kh6 (data not shown). Moreover, Jijakli and Lepoivre (1993) and Jijakli et al. $(1999,1993)$ demonstrated that $P$. anomala $\mathrm{K}$ exhibited a 93-97\% protection level against B. cinerea. The membrane also prevents the contaminations by apple constituents. No apple proteins were identified by MALDI-ToF mass spectrometry in the randomly chosen spots excised from $24 \mathrm{~cm} 2 \mathrm{D}$ gels (data not shown). Based on the growth time-course, samples were taken 7 and $24 \mathrm{~h}$ after yeast inoculation, i.e. during the respective exponential and stationary phases of $P$. anomala Kh6 growth on apples.

\section{Extraction protocols}

The extracted protein quantity and quality had to be compatible with the downstream proteomic study.

\section{Hot SDS/acetone versus urea/thiourea extraction protocol}

The higher UTprot-extracted protein yield at the stationary phase than at the exponential phase did not meet our expectations. Indeed, stationary phase yeast cells are physiologically, biochemically and morphologically distinct from exponentially growing cells. Stationary phase cells have thick and less porous cell walls (Nobel et al. 1990a, b) and the synthesis of most of the exponential phase proteins stops at the stationary phase (Boucherie 1985). In the exponential phase, the morphological and physiological state of $P$. anomala Kh6 cells possibly required more aggressive extraction conditions that were not present in UTprot. The higher protein yield in samples in the presence of $B$. cinerea could be explained by the introduction of the pathogen. Indeed, although $B$. cinerea growth was inhibited by $P$. anomala $\mathrm{Kh} 6$ (Jijakli et al. 1993), introducing pathogen conidia into yeast samples certainly contributed to increasing protein yield. Whatever the growth phases or the presence of the pathogen, SDSprot extracted more proteins than UTprot. SDSprot was designed to extract proteins from recalcitrant plant tissues like potato tubers and remove interfering compounds like polyphenols (Delaplace et al. 2006) whereas UTprot was developed for in vitro yeast studies (Fernández-Arenas et al. 2007; Gori et al. 2007; Hansen et al. 2006; Hu et al. 2003; Hwang et al. 2006; Kusch et al. 2007; Matis et al. 2005; Orsborn et al. 2006; Sinclair et al. 2006; Teixeira et al. 2005). P. anomala Kh6 seems to possess a highly resistant cellular wall implying the use of an aggressive lysis step, as in SDSprot, in addition to the extraction protocols commonly used for yeast cells (Massart 2005).

The obtained 1D gel patterns of SDSprot presented a majority of low MW proteins whereas UTprot gel showed a wide range of MW. These differences can be explained either by a higher capacity of SDSprot to extract low MW proteins as compared to UTprot, or by protein degradation induced by the presence of active proteases released during the lysis step in the SDSprot experiment in spite of the supposed irreversible inactivation of the SDSprot extracted proteases (des Francs et al. 1985; Harrison and Black 1982). However, the possible presence of residual polysaccharides in SDSprot extractions could as well explain these differences. Polysaccharides could narrow the gel pores and prevent the entry of high MW proteins in the gels. Similar results were previously reported (Delaplace et al. 2006).

The obtained 2D gel patterns using SDSprot and UTprot confirmed the observations from 1D gels. The 
slight smear observed on the 2D SDSprot gel for high MWs and acidic proteins could be due to the difficulty to solubilise them even in a buffer that is highly concentrated in chaotropes such as urea and thiourea (Harder et al. 1999). In spite of the difference in patterns, the 2D gel quality obtained with either of the extraction protocols was comparable and exploitable for further analysis.

\section{Urea/thiourea protocol modifications}

Unlike SDSprot, UTprot is a simple and rapid extraction protocol with good $1 \mathrm{D}$ and $2 \mathrm{D}$ gel patterns but has the disadvantage of extracting small amounts of proteins incompatible with the further use of large $2 \mathrm{D}$ gels. Consequently a series of optimizations was attempted in order to improve protein yield.

Adding a sonication step to UTprot increases protein yield. During sonication, the violent collapse of cavitation bubbles induces cell wall disruption (Tsukamoto et al. 2004). In addition to the mechanical damage caused by the beads, sonication may increase the number of lysed cells and then the yield of protein extraction. Longer sonication times did not increase the quantities of extracted proteins as we expected. Applying such a sonication for a long period results in a high local temperature and pressure (Suslick and Price 1999). These conditions could induce modifications of the binding site of the Bradford reagent (arginine, tyrosine, tryptophane, histidine or phenylalanine), and a resulting decrease in quantified protein concentrations (Brandts et al. 1970; Privalov and Makhatadze 1990). The results of the addition of a precipitation step are coherent with previous studies that demonstrated better protein extraction using phenol compared with TCA (Carpentier et al. 2005; Saravanan and Rose 2004; Vincent et al. 2006). TCA is a very effective precipitant, but TCA-precipitated proteins are more difficult to redissolve than phenolprecipitated proteins (Nandakumar et al. 2002). A quantitative comparison between acetone-, TCA- and a phenol-based precipitation step has not been emphasized in recent publications. However, a higher protein loss probably took place with TCA and phenol than with acetone. Although the precipitation step enables us to purify proteins and concentrate them by resuspending them in a lower volume of rehydration buffer, it could also imply protein loss.
A sonication or a precipitation step improved the extracted protein yield without however improving the 1D gels' quality. All the modifications 1D gels presented few resolved bands with weak intensity. These results were unexpected. A high rate of protein degradation (see above) could possibly explain the results of the four sonication protocols. However, even if the UTPHE pattern suggested proteins' degradation, the UTTCA and UTACE pattern suggested more a protein loss due to the precipitation step.

Likewise, the 2D gels' quality was not improved by the addition of a sonication or a precipitation step. This result could be explained either by proteins' degradation (UTS3) or loss of proteins (UTACE) (see above) or by nucleic acid contamination. Nucleic acids interact with proteins and can adversely affect the resolution of focusing gels (O'Farrell 1975). However, ultrasounds have harmful effects on nucleic acids (McKee et al. 1977) and acetone-based precipitation discards nucleic acids from the protein sample, which suggests the absence of nucleic acid contaminations in our protein extracts.

\section{$24 \mathrm{~cm} 2$ D electrophoresis gels}

To improve resolution and sensitivity of 2D gels, $24 \mathrm{~cm}$ IPG strips should be used in further studies. Such strips have a higher protein loading capacity and a higher separating power than $7 \mathrm{~cm}$ IPGs. Consequently an increased number of protein spots can be observed with the same sensitivity. Our results showed that UTprot and SDSprot were the most effective extraction protocols to obtain good quality 1D and $7 \mathrm{~cm} \mathrm{2D}$ gels. However, the low UTprot-extracted protein yield did not make it possible to load $100 \mu \mathrm{g}$ of protein on the $24 \mathrm{~cm} \mathrm{2D} \mathrm{gels.} \mathrm{Finally,} \mathrm{SDSprot} \mathrm{was}$ the most efficient protocol for the considered parameters. To confirm this choice, an assay on $24 \mathrm{~cm} \mathrm{2D}$ gels was performed. The $24 \mathrm{~cm} \mathrm{2D}$ pattern could be explained by the loading of $100 \mu \mathrm{g}$ of proteins, the higher separating power of the $24-\mathrm{cm}$ strips and the protein extract purity. The loading of high protein quantities increase the amount of low abundant proteins. Proteins with a closed pI can be separated on $24 \mathrm{~cm}$ strips in two resolved spots whereas one single spot is observed on a $7 \mathrm{~cm}$ strips. The precipitation step included in the SDSprot allowed to limit the salt or nucleic acids contaminations. In such condition, 2D gels presented a low background that 
did not impair the proteins' quantification. The $24-\mathrm{cm}$ 2D gels obtained from our in situ model and the proteins extracted using SDSprot could be used in a proteomic study confirming the choice of the extraction protocol.

Finally, this study aimed at developing an in situ model and an extraction protocol making it possible to analyse, during a first global approach, the inhibition mechanism of $P$. anomala Kh6 against $B$. cinerea in a proteomic study. The in situ model is close to natural infection conditions where interactions among host, antagonist and pathogen occur while limiting the contaminations by apple constituents. Moreover the inhibitory effect of $P$. anomala against $B$. cinerea is maintained.

In a proteomic study, protein extraction is a key step that determines 2D gel quality. The hot SDS lysis and the urea/thiourea extraction protocols gave different 2D patterns compatible with a proteomic study. However, SDSprot seems more efficient than UTprot in terms of protein extraction yield. An additional step of sonication or protein precipitation to the UTprot increased the quantity of extracted proteins but decreased the 1D and 2D gel quality. UTprot optimization could be carried on by improving the lysis buffer to increase the protein solubilization, by decreasing protein degradation by natural proteases or by a combination of a thermal lysis and a precipitation step. In our conditions, SDSprot, which combined thermal and mechanical lysis with a protein precipitation step, remained the most effective protocol to extract proteins. The developed model and the extraction protocol allow the recovery of yeast proteins in amounts and in quality compatible with the downstream proteomic study of the biocontrol mechanism of $P$. anomala Kh6.

Acknowledgments This work was supported by the Belgian Fond National de la Recherche Scientifique (FNRS, FRFC 2.4.574.08.F convention). The authors wish to thank Sergio Mauro, Marianne Cranshof, Sébastien Séha and Grégory Lafalize for their help.

\section{References}

Boucherie H (1985) Protein synthesis during transition and stationary phases under glucose limitation in Saccharomyces cerevisiae. J Bacteriol 161:385-392

Bradford MM (1976) A rapid and sensitive method for the quantitation of migrogram quantities of protein utilizing the principle of protein-dye binding. Anal Biochem 72: 248-254

Brandts JF, Oliveira RJ, Westort C (1970) Thermodynamics of protein denaturation. Effect of pressure on the denaturation on ribonuclease A. Biochemistry 9:1038-1047

Carpentier SC, Witters E, Laukens K, Deckers P, Swennen R, Panis B (2005) Preparation of protein extracts from recalcitrant plant tissues: an evaluation of different methods for two-dimensional gel electrophoresis analysis. Proteomics 5:2497-2507

Delaplace P, van der Wall F, Dierick J-F, Cordewener JHG, Fauconnier M-LP, du Jardin P, America AHP (2006) Potato tuber proteomics: comparison of two complementary extraction methods designed for 2-DE of acidic proteins. Proteomics 6:6494-6497

des Francs CC, Thiellement H, De Vienne D (1985) Analysis of leaf proteins by two-dimensional gel electrophoresis: protease action as exemplified by ribulose bisphosphate carboxylase/oxygenase degradation and procedure to avoid proteolysis during extraction. Plant Physiol 78:178-182

Fernández-Arenas E, Cabezón V, Bermejo C, Arroyo J, Nombela C, Diez-Orejas R, Gil C (2007) Integrated proteomics and genomics strategies bring new insight into Candida albicans response upon macrophage interaction. Mol Cell Proteomics 6:460-478

Friel D, Pessoa NMG, Vandenbol M, Jijakli MH (2007) Separate and combined disruptions of two exo- $\beta$-1,3-glucanase genes decrease the efficiency of Pichia anomala (strain K) biocontrol against Botrytis cinerea on apple. Mol Plant Microbe Interact 20:371-379

Görg A, Weiss W, Dunn MJ (2004) Current two-dimensional electrophoresis technology for proteomics. Proteomics 4: 3665-3685

Gori K, Hébraud M, Chambon C, Mortensen HD, Arneborg N, Jespersen L (2007) Proteomic changes in Debaryomyces hansenii upon exposure to $\mathrm{NaCl}$ stress. FEMS Yeast Res 7:293-303

Grevesse C, Lepoivre P, Jijakli MH (2003) Characterization of the exoglucanase-encoding gene PaEXG2 and study of its role in the biocontrol activity of Pichia anomala strain K. Phytopathology 93:1145-1152

Hansen R, Pearson S, Brosnan J, Meaden P, Jamieson D (2006) Proteomic analysis of a distilling strain of Saccharomyces cerevisiae during industrial grain fermentation. Appl Microbiol Biotechnol 72:116-125

Harder A, Wildgruber R, Nawrocki A, Fey SJ, Larsen PM, Görg A (1999) Comparison of yeast cell protein solubilization procedures for two-dimensional electrophoresis. Electrophoresis 20:826-829

Harrison PA, Black CC (1982) Two-dimensional electrophoretic mapping of proteins bundle sheath and mesophyll cells of the C4 grass Digitaria sanguinalis (L.) Scop (Cabgrass). Plant Physiol 70:1359-1366

Hu Y, Wang G, Chen GYJ, Fu X, Yao SQ (2003) Proteome analysis of Saccharomyces cerevisiae under metal stress by two-dimensional differential gel electrophoresis. Electrophoresis 24:1458-1470

Hwang K-H, Carapito C, Böhmer S, Leize E, van Dorsselaer A, Bernhardt R (2006) Proteome analysis of Schizosaccharomyces pombe by two-dimensional gel electrophoresis and mass spectrometry. Proteomics 6:4115-4129 
Jijakli HM, Lepoivre P (1993) Biological control of postharvest Botrytis cinerea and Penicillium on apples. IOBC/WRPS Bulletin: Biol control foliar Post-harvest Dis 16:106-110

Jijakli MH, Lepoivre P (1998) Characterization of an exo- $\beta$-1,3glucanase produced by Pichia anomala strain K, antagonist of Botrytis cinerea on apples. Phytopathology 88:335-343

Jijakli MH, Lepoivre P, Tossut P, Thonart P (1993) Biological control of Botrytis cinerea and Penicillium on postharvest apples by two antagonistic yeasts. Med Fac Landbouwwet Univ Gent 58:1349-1358

Jijakli MH, Lepoivre P, Grevesse C (1999) Yeast species for biocontrol of apples postharvest diseases: an encouraging case of study for practical use. In: Mukerji KG, Chamola BP, Upadhay RK (eds) Biotechnological approaches in biocontrol of plant pathogens. Academic/Plenum, New York, USA, pp 31-49

Kusch H, Engelmann S, Albrecht D, Morschhäuser J, Hecker M (2007) Proteomic analysis of the oxidative stress response in Candida albicans 13. Proteomics 7:686-697

Massart S (2005) Identification par la cDNA-AFLP de gènes potentiellement impliqués dans les propriétés de biocontrôle de la levure Pichia anomala (Hansen) Kurtzman (souche Kh5), un agent antagoniste de Botrytis cinerea Pers. sur pomme en conservation. Académie Universitaire Wallonie-Europe, Fusagx, Gembloux, Belgium, p 187

Massart S, Jijakli MH (2006) Identification of differentially expressed genes by cDNA-amplified fragment length polymorphism in the biocontrol agent Pichia anomala (strain Kh5). Phytopathology 96:80-86

Matis M, Žakelj-Mavrič M, Peter-Katalinić J (2005) Global analysis of the Hortaea werneckii proteome: studying steroid response in yeast. J Proteome Res 4:2043-2051

McKee JR, Christman CL, O'Brien WD, Wang SY (1977) Effects of ultrasound on nucleic acid bases. Biochemistry 16:4651-4654

Nandakumar MP, Shen J, Raman B, Marten MR (2002) Solubilization of trichloroacetic acid (TCA) precipitated microbial proteins via $\mathrm{NaOH}$ for two-dimensional electrophoresis. J Proteome Res 2:89-93

Nobel JGD, Klis FM, Munnik T, Priem J, Ende HVD (1990a) An assay of relative cell wall porosity in Saccharomyces cerevisiae, Kluyveromyces lactis and Schizosaccharomyces pombe. Yeast 6:483-490

Nobel JGD, Klis FM, Priem J, Munnik T, Ende HVD (1990b) The glucanase-soluble mannoproteins limit cell wall porosity in Saccharomyces cerevisiae. Yeast 6:491-499

O'Farrell PH (1975) High resolution two-dimensional electrophoresis of proteins. J Biol Chem 250:4007-4021

Orsborn KI, Shubitz LF, Peng T, Kellner EM, Orbach MJ, Haynes PA, Galgiani JN (2006) Protein expression profiling of Coccidioides posadasii by two-dimensional differential in-gel electrophoresis and evaluation of a newly recognized peroxisomal matrix protein as a recombinant vaccine candidate. Infect Immun 74:1865-1872

Privalov PL, Makhatadze GI (1990) Heat capacity of proteins: II. Partial molar heat capacity of the unfolded polypeptide chain of proteins: protein unfolding effects. J Mol Biol 213: 385-391

Saravanan RS, Rose JKC (2004) A critical evaluation of sample extraction techniques for enhanced proteomic analysis of recalcitrant plant tissues. Proteomics 4:2522-2532

Shaw MM, Riederer BM (2003) Sample preparation for twodimensional gel electrophoresis. Proteomics 3:1408-1417

Sholberg PL, Haag PD (1996) Incidence of postharvest pathogens of stored apples in British Columbia. Can J Plant Pathol 18:81-85

Sinclair J, Weeks M, Butt A, Worthington JL, Akpan A, Jones N, Waterfield M, Allanand D, Timms JF (2006) Proteomic response of Schizosaccharomyces pombe to static and oscillating extremely low-frequency electromagnetic fields. Proteomics 6:4755-4764

Suslick KS, Price GJ (1999) Application of ultrasound to materials chemistry. Annu Rev Mater Sci 29:295-326

Teixeira MC, Santos PM, Fernandes AR, Sá-Correia I (2005) A proteome analysis of the yeast response to the herbicide 2,4-dichlorophenoxyacetic acid. Proteomics 5:1889-1901

Tsukamoto I, Constantinoiu E, Furuta M, Nishimura R, Maeda $\mathrm{Y}$ (2004) Inactivation effect of sonication and chlorination on Saccharomyces cerevisiae calorimetric analysis. Ultrason Sonochem 11:167-172

Vincent D, Wheatley MD, Cramer GR (2006) Optimization of protein extraction and solubilization for mature grape berry clusters. Electrophoresis 27:1853-1865

\section{Author Biographies}

Anthony Kwasiborski carried out this study as part of his post- $\mathrm{PhD}$ devoted to the proteomic analysis, on an in situ model, of the mode of action of the yeast Pichia anomala, an antagonist of the apple pathogen Botrytis cinerea.

Mohamed Bajji is involved in the elaboration of genetical strategies improving cultivated plant within the Walloon Agricultural Research Centre.

Pierre Delaplace is studying on one hand the post-harvest ageing of potatoes and on the other hand the plant growth promotion by rhizobacterial volatile organic compounds emitted in the rhizosphere.

Patrick du Jardin leads the Plant Biology Unit within the university of Liège and works on the characterization and conservation of tropical plants biodiversity and studies the metabolism and development of agricultural plants.

Haïssam M. Jijakli leads the Plant Pathology Unit within the university of Liège and works on the development of alternative methods to control diseases of plants and biopesticides and biofertilisers market in Benelux. 